\title{
Optimal Strategy of Supply Chain considering Interruption Insurance
}

\author{
Rong Yu (D), Zhong Wu (D), and Shaojian Qu (iD \\ Business School, University of Shanghai for Science and Technology, Shanghai 200093, China \\ Correspondence should be addressed to Zhong Wu; wuzhong_1968@163.com
}

Received 18 March 2021; Revised 6 April 2021; Accepted 9 April 2021; Published 23 April 2021

Academic Editor: Wei Zhang

Copyright $(\odot 2021$ Rong Yu et al. This is an open access article distributed under the Creative Commons Attribution License, which permits unrestricted use, distribution, and reproduction in any medium, provided the original work is properly cited.

\begin{abstract}
The interruption of supply chain caused by unexpected events results in great economic losses. In this paper, we consider that the supply chain risk management consists of a manufacturer and a retailer faced with demand and supply uncertainties caused by the interruption of supply chain. We consider that the manufacturer transfers the disruption risk by purchasing BI (business interruption) insurance. Three models are established to illustrate the impact of insurance on supply chain decision-making under risk. It is observed that business interruption insurance can increase the retailer's order quantity and supply chain profit. The higher the interrupt probability is, the more obvious the value of the business interruption insurance is. Furthermore, the retailer helps the manufacturer to share the premium, and the manufacture shares the proceeds of insurance with the retailer, which can stimulate retailer to order more and increase the profit of manufacturer and retailer.
\end{abstract}

\section{Introduction}

In recent years, various emergencies and disasters (such as fire, earthquake, and flood) are impacting the supply chain more and more frequently, and the globalization of the supply chain further aggravates the risk of the supply chain, especially the supply risk. Procurement is at the source of the whole supply chain, which plays a vital role in the survival and development of enterprises. The operation process of supply chain will be affected by various factors, and there are also various forms of risks. Supply interruption is one of the many risks, which makes the downstream enterprises of the supply chain suffer from excessive downtime due to the lack of production resources and even disconnects the upstream and downstream supply chains and finally brings about huge economic losses to enterprises. BI insurance, as an important tool for enterprises to cope with risk management, has been effectively applied in practice. For example, Ericsson mobile division lost $\$ 1.68$ billion as a result of a fire at the Philips plant in 2000; it received $\$ 200$ million from the insurance company. After the Wenchuan earthquake, Lafarge company also received $\$ 720$ million by purchasing BI insurance. BI insurance provides a strong guarantee for companies when they face interruption risks, reduces their risk coefficients, and improves their antirisk capabilities. Therefore, it is of great significance to introduce BI insurance into the supply chain. This paper will discuss the impact of the purchase BI insurance by manufacturers on the decision of supply chain members under the risk of disruption.

However, there are few studies on BI insurance, and most of the literatures focus on insurance regulations. Furman and Zitikis [1] considered a prominent problem in actuarial science, defining or describing premium calculation principles that meet certain characteristics, and they derived explicit formulas for weighted premium distribution of loss in several important categories, thus facilitating parameter statistical inference. Dong and Tomlin [2] discussed the relationship between commercial insurance and operation measures and proved that insurance and operation measures are not always substitutes for each other. Under certain conditions, insurance can increase the marginal value of inventory and the overall value of emergency procurement. Later, Dong and Tang [3] considered that a company can purchase BI insurance, implement storage inventory, or take preparatory actions to reduce the expected interruption time and analyzed how the insurance affects the 
optimal deployment and preference of these two operational measures. Zhen et al. [4] studied the effect of ex ante BI insurance on ex post transportation recovery and compared ex ante BI insurance with ex post action backup transportation. Stecke and Kumar [5] considered through buying BI insurance to address supply chain risk. Their research shows that when the premium is high and the purchase of BI insurance cannot make up for the decline of the market share of the insured enterprise, the risk transfer through this insurance is not suitable for the small and relatively weak enterprises. Lodree and Taskin [6] studied the optimal inventory level under the uncertainty of demand and extreme event and combines insurance policy with active disaster relief planning, which provides a practical method for decision-makers to quantify the inventory level, premium and income under interruption. Tierney [7] analyzed the value of $\mathrm{BI}$ insurance in dealing with risks according to actual cases and discussed the role of BI insurance in the Northridge earthquake. Lin et al. [8] proposed an insurance contract under which suppliers and retailers share the risk of overstock and understock. It proved for the first time that the insurance contract can coordinate the supply chain. On this basis, it compares the insurance contract with the incomesharing contract and focused on the analysis of the differences between the insurance contract and the incomesharing contract. Commercial insurance is traditionally based on a single enterprise as the research background. However, Serpa and Krishnan [9] studied commercial insurance in the context of several companies and believe that insurance can be strategically used as a commitment mechanism to improve the efficiency of risk management by reducing free-rider problems. Alex and Birge [10] studied how commercial credit plays a risk-sharing role in supply chain. When retailers are well funded, interest-free credit is appropriate, and when funding is constrained, suppliers offer two-phase contracts. Most of the above articles mainly study the complementary relationship between insurance and multisource procurement, inventory, as well as some study on insurance clauses. The difference between our paper and the previous literature is that we introduce BI insurance into the supply interruption model and discuss the changes of the optimal wholesale price and optimal order quantity under the three cases of the manufacturer not purchasing insurance, separately purchasing insurance, and the retailer helping the manufacturer to share the premium.

Recently, there are many measures to deal with the risk of interruption, which are mainly divided into the three following categories: inventory management, multisource purchasing, and business interruption insurance. Yang et al. [11], Hu et al. [12], Tomlin [13], and Tang et al. [14] mainly studied the supply chain disruption under the strategies of inventory holding, multisupplier procurement, and alternative supply/backup production from the perspective of retailers. The literature on multiple sources is very rich. Babich et al. [15] considered a retailer facing random market demand and random supply who adopts two competitive suppliers to supply in order to increase the stability of supply; they studied how a retailer chooses suppliers and formulates pricing and purchasing strategies. Aissaoui et al.
[16] pointed out that multisource procurement can prevent the shortage of purchaser resources and make the competition between suppliers firm. Sarkar and Mohapatra [17] divided the emergencies into system emergencies, local emergencies, and individual emergencies and used the method of decision tree to determine the optimal number of suppliers. Meena and Sarmah [18] studied the problem of supplier selection under different interruption risks and established an optimal supplier selection model with different failure probability, capacity, and compensation. The numerical study and sensitivity analysis provide useful guidance for managers to select the optimal supplier number under supply interruption risks. Xanthopoulos et al. [19] proposed a single-cycle inventory model for decisionmakers of risk neutrality and risk aversion, and the advantages of contingency strategy in managing uncertainty and risk in dual supply chain are discussed. Lu et al. [20] considered a supply chain with two replaceable products and two suppliers, and products can be ordered from an unreliable supplier or a reliable but more expensive supplier. It is found that, in the optimal procurement strategy, the highgrade products should be superior to the low-end products, and the demand variability and correlation have an impact on the substitution effect of products and the corresponding optimal procurement strategy. Li et al. [21] focused on the impact of the use of dual-source procurement strategies on inventory status, recovery of production capacity, and varying degrees of supply disruption. They analyzed the profit function of manufacturers under different degrees of supply interruption and provided theoretical basis for whether and how to use dual-source procurement strategy under different degrees of supply interruption risk. When facing supply disruptions, the emergency procurement strategy and the optimal allocation procurement strategy are widely used strategies to manage supply risks. Yin and Wang [22] considered the three common purchasing methods between the retailer and the main supplier and the standby supplier: prepurchase, reservation, and emergency purchase; they gave the optimal ordering mode of the retailer under different interruption probability. After that, Wang and Yin [23] considered the procurement problem of a risk-averse retailer with two suppliers, and, in order to reduce the risk of interruption, the retailer adopted a joint backup supply and responsive pricing strategy. Three common backup strategies between the retailer and the backup provider are studied: prepurchase, reservation, and emergency purchase; they deduced the conditions under which each strategy is optimal and the impact of different risk attitudes on the retailer's ordering strategy. He et al. [24] considered that the retailer adopts emergency procurement and optimal allocation strategies under the threat of supply disruption and price competition; they analyzed the effects of reliability level and cost on equilibrium price, expected profit, and equilibrium strategy allocation.

In the strategy of supply chain risk management, inventory can make enterprises maintain continuous and stable production and supply as far as possible in case of interruption, reduce the contradiction between supply and demand to a certain extent, and reduce the negative effect 
brought about by supply chain risk. Making appropriate inventory strategy is a common way for enterprises to deal with supply chain risks under multicycle model or continuous model [25]. Parlar and Berkin [26] assumed that both supply normal time and supply interruption time follow exponential distribution and are independent random variables and studied the EOQ problem of a secondary supply chain. In view of the uncertainty of upstream enterprises supply capacity, Khang and Fujiwara [27] studied the downstream enterprises' strategies based on the market demand, initial inventory, and upstream enterprises' supply capacity. Zhou et al. [28] explored the optimal ordering strategy in a secondary supply chain composed of a riskaverse manufacturer and a risk-averse retailer. Yan et al. [29] studied the effects of channel structure, risk-averse attitude, and scale of the demand disruption on a dual-channel supply chain. Zhao and Zhu [30] explored the risk-averse marking strategy in a remanufacturing supply chain.

This paper mainly studies the value of insurance coping with supply chain interruption risk by establishing three models: manufacturer does not buy BI insurance, purchases insurance separately, and retailer shares the premium. We explored the impact of outage probability on the optimal decision-making of a company. The main contributions of this paper can be summarized as follows: Firstly, in the background of uncertain market demand, we study the impact of introducing BI insurance on the decision-making of retailers in the face of uncertain demand and supply. Secondly, most of the studies on insurance focus on the formulation of insurance policies and clauses, while the research in this paper mainly combines insurance and interruption risk management to study the impact of interruption probability on enterprise decision-making. Finally, we study the effect of business interruption insurance on wholesale price of manufacturers and order quantity of retailers under the shortage of punishment mechanism.

\section{The Model}

2.1. Notations and Assumptions. A secondary supply chain consisting of manufacturers and retailers is considered. Without loss of generality, we assume that the manufacturer delivers the goods to its retailer, and the retailer purchases only a single product from the manufacturer. The retailer's decision problem is to decide the optimal quantity to order, and the retailer faces random market demand $D$ (probability density function is $f(x)$ and cumulative distribution function is $F(x)$ ). Due to various natural disasters or equipment failure and other uncertainties of external environment, manufacturer are faced with the risk of supply interruption with a probability $\alpha$. Once the interruption occurs, the manufacturer can only supply part of the goods to the retailer, and the supply factor is $k(0<k<1)$. When the manufacturer fails to meet the retailer's order demand, he will face punishment, the punishment for unit product out of stock is $h$, and the production cost is $c$. Firstly, the manufacturer sets the wholesale price $w$, and then the retailer considers the uncertainty on both sides of supply and demand to order. Finally, the manufacturer produces and supplies to the retailer, and the retailer decides the sales price $p$ according to the market.

The notations used in the paper are provided in Table 1. Consider the following assumptions:

(1) Manufacturer and retailer are risk neutral, and both aim to maximize their profits

(2) Supply risks aim at manufacturers' finished goods (e.g., transportation damage, finished goods warehouse fire, etc.), resulting in random delivery by manufacturers, but production costs have occurred

(3) The premium rate is exogenous, and the indemnity period is within the maximum indemnity period of the insurance contract

(4) The information among the members of the supply chain is symmetrical

2.2. Uninsured Model without Disruption. Considering a secondary supply chain composed of a manufacturer and a retailer, the retailer faces random market demand $D(f(x)$ is the probability density function and $F(x)$ is the cumulative distribution function). In this section, the model does not consider the interruption of the manufacturer. The unit production cost of the manufacturer is $c$. Both parties enter into a wholesale price contract, and the manufacturer sets the wholesale price; according to the market demand, the retailer determines the order quantity and sells the products. The retailer's profit function is

$$
\begin{aligned}
\pi_{r} & =p \min (q, D)-w q, \\
E\left(\pi_{r}\right) & =p\left(q-\int_{0}^{q} F(x) \mathrm{d} x\right)-w q,
\end{aligned}
$$

and when the random market demand obeys uniform distribution $[a, b]$, the retailer's profit can be rewritten as

$$
E\left(\pi_{r}\right)=(p-w) q+\frac{a p q}{b-a}-\frac{p q^{2}}{2(b-a)} .
$$

The profit function of manufacturer is

$$
E\left(\pi_{m}\right)=(w-c) q .
$$

Theorem 1. There is a unique optimal order quantity and wholesale price that maximizes the retailer's and manufacturer's profit. The optimal solutions are as follows:

$$
\begin{gathered}
w^{*}=\frac{p b+c b-c a}{2(b-a)}, \\
q^{*}=\frac{p b-c b+c a}{2 p}, \\
E\left(\pi_{r}^{*}\right)=\frac{(p b-c b+c a)^{2}}{8 p(b-a)}, \\
E\left(\pi_{m}^{*}\right)=\frac{(p b-c b+c a)^{2}}{4 p(b-a)} .
\end{gathered}
$$


TABLE 1: Symbols and related descriptions.

\begin{tabular}{lc}
\hline Notations & Description \\
\hline$w$ & Wholesale price of manufacturer \\
$p$ & Retail price \\
$c$ & Production cost of manufacturer \\
$q$ & Retailer's order quantity \\
$D$ & Random market demand \\
$f(x)$ & Probability density function of demand \\
$F(x)$ & Cumulative distribution function of demand \\
$\alpha$ & Probability of interruption \\
$k$ & Random supply factor \\
$h$ & Penalty cost per unit product \\
$r$ & Premium rate \\
$\beta$ & Premium sharing coefficient \\
$\gamma$ & Insurance proceeds sharing coefficient \\
$E\left(\pi_{r}\right)$ & The expected profit function of retailer \\
$E\left(\pi_{m}\right)$ & The expected profit function of manufacturer \\
\hline
\end{tabular}

Proof. The first and second derivatives of the profit function (2) are

$$
\begin{aligned}
\frac{\mathrm{d} \pi_{r}}{\mathrm{~d} q} & =p-w+\frac{a p}{b-a}-\frac{p q}{b-a}, \\
\frac{\mathrm{d}^{2} \pi_{r}}{\mathrm{~d} q^{2}} & =-\frac{p}{b-a}<0,
\end{aligned}
$$

and, according to the last inequality, we know that retailer's profit is a concave function of order quantity. Let the firstorder derivative be equal to 0 , we get

$$
q=\frac{a p+(b-a)(p-w)}{p}
$$

substituting (6) into equation (3), and the first and second derivatives of (3) are

$$
\begin{aligned}
\frac{\mathrm{d} \pi_{m}}{\mathrm{~d} w} & =b+\frac{(b-a)(2 w-c)}{p}, \\
\frac{\mathrm{d}^{2} \pi_{m}}{\mathrm{~d} w^{2}} & =-\frac{2(b-a)}{p}<0 .
\end{aligned}
$$

The manufacturer's profit is a concave function of wholesale price. Let the first-order derivative be equal to 0 , we get

$$
w^{*}=\frac{c b+p b-c a}{2(b-a)} .
$$

Substituting (8) into (6), we have

$$
q^{*}=\frac{p b-c b+c a}{2 p} \text {. }
$$

Put (8) and (9) into the profit formula of retailer and manufacturer, we can get that

$$
\begin{aligned}
& E\left(\pi_{r}^{*}\right)=\frac{(p b-c b+c a)^{2}}{8 p(b-a)}, \\
& E\left(\pi_{m}^{*}\right)=\frac{(p b-c b+c a)^{2}}{4 p(b-a)} .
\end{aligned}
$$

This completes the proof.

2.3. Uninsured Model with Disruption. In this section, we study the case where the manufacturer does not purchase BI insurance; due to the occurrence of various emergencies, the manufacturer is faced with the risk of interruption, the probability of interruption is $\alpha$, and the supply factor is $k(0<k<1)$. When the supply quantity of the manufacturer is less than the order quantity of the retailer, the manufacturer will face the penalty of out of stock, and the penalty cost of unit product is $h$. The two sides enter into a wholesale price contract, the manufacturer first determines the wholesale price, and the retailer makes a purchase decision considering the uncertainty of supply and demand.

The retailer's profit function is

$$
\begin{aligned}
\pi_{r}= & (1-\alpha)[p \min (q, D)-w q]+\alpha[p \min (k q, D) \\
& -w k q+h(1-k) q], \\
E\left(\pi_{r}\right)= & v_{1}(p-w) q-(1-\alpha) p \int_{0}^{q} F(x) \mathrm{d} x \\
& -\alpha p \int_{0}^{k q} F(x) \mathrm{d} x+\alpha h(1-k) q,
\end{aligned}
$$

where $v_{1}=1-\alpha+\alpha k$; when the random market demand obeys uniform distribution $[a, b]$, the retailer's profit can be rewritten as

$$
E\left(\pi_{r}\right)=v_{1}(p-w) q-\frac{v_{2} p q^{2}}{2(b-a)}+\frac{v_{1} a p q}{b-a}+\alpha h(1-k) q
$$

where $v_{2}=1-\alpha+\alpha k^{2}$.

The expected profit function of manufacturer is

$$
\pi_{m}=(1-\alpha)(w-c) q+\alpha[(w-c) k q-h(1-k) q] .
$$

Theorem 2. There is a unique optimal order quantity and wholesale price that maximizes the expected profit function. The optimal policies are as follows: 


$$
\begin{aligned}
q^{*} & =\frac{v_{1}(p b-c b+c a)}{2 p v_{2}}, \\
w^{*} & =\frac{c b+p b-c a}{2(b-a)}+\frac{\alpha h(1-k)}{v_{1}}, \\
E\left(\pi_{r}^{*}\right) & =\frac{\left[v_{1}(p b-c b+c a)\right]^{2}}{8 p v_{2}(b-a)}, \\
E\left(\pi_{m}^{*}\right) & =\frac{\left[v_{1}(p b-c b+c a)\right]^{2}}{4 p v_{2}(b-a)} .
\end{aligned}
$$

Proof. The first and second derivatives of the profit function (12) are

$$
\begin{aligned}
\frac{\mathrm{d} \pi_{r}}{\mathrm{~d} q} & =v_{1}(p-w)+\alpha h(1-k)-\frac{v_{2} p q}{b-a}+\frac{v_{1} a p}{b-a}, \\
\frac{\mathrm{d}^{2} \pi_{r}}{\mathrm{~d} q^{2}} & =-\frac{v_{2} p}{b-a}<0 .
\end{aligned}
$$
have

Let the first-order derivative of (12) be equal to 0 , we

$$
q=\frac{v_{1} b p+\alpha h(1-k)(b-a)-v_{1}(b-a) w}{v_{2} p} .
$$

Similarly, we obtain the optimal wholesale price:

$$
w^{*}=\frac{c b+p b-c a}{2(b-a)}+\frac{\alpha h(1-k)}{v_{1}} .
$$

Substituting (17) into equation (16), we get

$$
q^{*}=\frac{v_{1}(p b-c b+c a)}{2 p v_{2}}
$$

Put equations (17) and (18) into formulas (12) and (13) to get the optimal profit for the manufacturer and retailer.

This completes the proof.

Proposition 1. The wholesale price of the manufacturer and the order quantity of retailer in case of interruption are greater than those without interruption.

Proposition 1 indicates that when the manufacturer is at risk of interruption, both the order quantity of the retailer and the wholesale price of the manufacturer will increase. The manufacturer has to bear the cost of interruption penalty in the event of interruption, and the manufacturer is bound to raise the wholesale price to offset the impact of the penalty.
2.4. Manufacturer's Individual Insurance. As an effective tool for risk management, BI insurance is widely used in real life, and many companies deal with the risk of disruption by buying insurance. We consider that the manufacturer buys $\mathrm{BI}$ insurance when he is at risk of interruption, and when the interruption occurs, the manufacturer can only supply the quantity of $k q$ to the retailer, and $k(0<k<1)$ is the supply factor. The manufacturer and retailer enter into a wholesale price contract, which contains a penalty clause for interruption. The manufacturer first determines the wholesale price, and the retailer decides the order quantity according to the uncertainty of supply and demand.

Here, we assume that BI insurance only considers purchase for the manufacturer's profit under normal production conditions, and the premium rate is $r$. Under normal production conditions, the manufacturer's profit is $(w-c) q$. When the disruption occurs, the manufacturer's profit is $(w-c) k q$, so the insured amount is $r(w-c) q$. In the event of interruption, the insurance company will compensate the manufacturer for the loss of profits, and the compensation amount is $(1-k)(w-c) q$. In addition, the precondition for manufacturer to buy insurance is that the compensation amount of the insurance company must be greater than the manufacturer's insurance amount; that is, $\alpha(w-c)(1-k) q>r(w-c) q$; namely, $\alpha(1-k)>r$; otherwise, the manufacturer does not buy insurance.

The retailers profit is

$$
\begin{aligned}
\pi_{r}= & (1-\alpha)[p \min (q, D)-w q]+\alpha[p \min (k q, D) \\
& -w k q+h(1-k) q], \\
E\left(\pi_{r}\right)= & v_{1}(p-w) q-(1-\alpha) p \int_{0}^{q} F(x) \mathrm{d} x \\
& -\alpha p \int_{0}^{k q} F(x) \mathrm{d} x+\alpha h(1-k) q .
\end{aligned}
$$

When the random market demand obeys uniform distribution $[a, b]$, the retailer's profit can be rewritten as

$$
E\left(\pi_{r}\right)=v_{1}(p-w) q-\frac{v_{2} p q^{2}}{2(b-a)}+\frac{v_{1} m p q}{b-a}+\alpha h(1-k) q .
$$

The manufacturer's profit is

$$
\begin{aligned}
E\left(\pi_{m}\right)= & (1-\alpha)(w-c) q+\alpha[(w-c) k q-h(1-k) q \\
& +(w-c)(1-k) q]-r(w-c) q .
\end{aligned}
$$


Theorem 3. There is a unique optimal order quantity and wholesale price maximizing the expected profit function. The optimal policies are as follows:

$$
\begin{aligned}
q^{*} & =\frac{v_{1}(p b-c b+c a)}{2 p v_{2}}+\frac{\alpha h(1-k)(b-a)\left(v_{4}-v_{1}\right)}{2 p v_{2} v_{4}} ; \\
w^{*} & =\frac{c b+p b-c a}{2(b-a)}+\frac{\alpha h(1-k)\left(v_{1}+v_{4}\right)}{2 v_{1} v_{4}} ; \\
E\left(\pi_{r}\right) & =\left[\frac{v_{1}(p b-c b+c a)}{4(b-a)}+\frac{\alpha h(1-k)\left(v_{4}-v_{1}\right)}{4 v_{4}}\right] q^{*} ; \\
E\left(\pi_{m}\right) & =\left[\frac{v_{4}(p b-c b+c a)}{2(b-a)}+\frac{\alpha h(1-k)\left(v_{4}-v_{1}\right)}{2 v_{1}}\right] q^{*} .
\end{aligned}
$$

Proof. Let $v_{4}=1-r$; through $\alpha(1-k)>r$, we can derive $1-\alpha+\alpha k<1-r$; that is, $v_{4}>v_{1}>v_{2}$. It is easy to verify that

$$
\begin{aligned}
\frac{\mathrm{d} \pi_{r}}{\mathrm{~d} q} & =v_{1}(p-w)-\frac{v_{2} p q}{b-a}+\frac{v_{1} a p}{b-a}+\alpha h(1-k), \\
\frac{\mathrm{d}^{2} \pi_{r}}{\mathrm{~d} q^{2}} & =-\frac{v_{2} p}{b-a}<0 .
\end{aligned}
$$

The optimal order quantity must satisfy the first-order condition $\left(\mathrm{d} \pi_{r} / \mathrm{d} q\right)=0$; then we have

$$
q=\frac{v_{1} b p+\alpha h(1-k)(b-a)-v_{1}(b-a) w}{v_{2} p} .
$$

Similarly,

$$
\frac{\mathrm{d}^{2} \pi_{m}}{\mathrm{~d} w^{2}}=-\frac{2(b-a)(1-r)}{p v_{2}}<0 .
$$

Let $\left(\mathrm{d} \pi_{m} / \mathrm{d} w\right)=0$, we have

$$
w^{*}=\frac{c b+p b-c a}{2(b-a)}+\frac{\alpha h(1-k)\left(v_{1}+v_{4}\right)}{2 v_{1} v_{4}} \text {. }
$$

Take $w^{*}$ into $q$, we get

$q^{*}=\frac{v_{1}(p b-c b+c a)}{2 p v_{2}}+\frac{\alpha h(b-a)(1-k)\left(v_{4}-v_{1}\right)}{2 p v_{2} v_{4}}$.

In addition, we can derive that

$$
\begin{aligned}
& E\left(\pi_{r}\right)=\left[\frac{v_{1}(p b-c b+c a)}{4(b-a)}+\frac{\alpha h(1-k)\left(v_{4}-v_{1}\right)}{4 v_{4}}\right] q^{*}, \\
& E\left(\pi_{m}\right)=\left[\frac{v_{4}(p b-c b+c a)}{2(b-a)}+\frac{\alpha h(1-k)\left(v_{4}-v_{1}\right)}{2 v_{1}}\right] q^{*} .
\end{aligned}
$$

This completes the proof.
Proposition 2. When the manufacturer buys BI insurance, the wholesale price is less than that in the case where the manufacturer does not buy the insurance, and the order quantity of the retailer and the profit of both the manufacturer and the retailer are also greater than those in the case where the manufacturer does not buy the insurance.

Proposition 2 indicates that, compared with no insurance, the wholesale price is lower and the order quantity is increased, and the profit of both the manufacturer and the retailer is greater than the profit without insurance, which indicates that the BI insurance effectively transfers the impact of interruption risk. With the interruption penalty, the manufacturer will always raise the wholesale price, but when the manufacturer buys the insurance, the manufacturer will get the insurance compensation in case of the interruption, which can be used for the penalty expenditure. Therefore, the manufacturer will reduce the increase of the wholesale price to stimulate the retailer to order more goods.

2.5. Premium Sharing Model for Manufacturers and Retailers. Since the amount of BI insurance is relatively large and the manufacturer wants to involve the retailer, the manufacturer will determine a premium apportionment ratio $\beta$ and enables the retailer to obtain the insurance income with coefficient $\gamma$. At the same time, the insurance income obtained by the retailer from the manufacturer must be greater than its own apportioned premium; that is, $\alpha \gamma(1-k)(w-c) q>\beta r(w-c) q$, so from this we can know that $\alpha \gamma(1-k)>\beta r$. In addition, for the manufacturer, the benefit from the insurance is greater than the amount of insurance he buys; that is, $(1-\beta) r(w-c) q<\alpha(1-\gamma)(1-k)(w-c) q$, which is equivalent to $(1-\beta) r<\alpha(1-\gamma)(1-k)$ Let $v_{3}=\alpha \gamma(1-k)-\beta r$, we can derive $v_{4}>v_{3}$.

The retailer's profit is

$$
\begin{aligned}
E\left(\pi_{r}\right)= & v_{1}(p-w) q-(1-\alpha) p \int_{0}^{q} F(x) \mathrm{d} x \\
& -\alpha p \int_{0}^{k q} F(x) \mathrm{d} x+\alpha h(1-k) q \\
& +[\alpha \gamma(1-k)-\beta r](w-c) q
\end{aligned}
$$

and when the random market demand obeys uniform distribution $[a, b]$, the retailer's profit can be rewritten as

$$
\begin{aligned}
E\left(\pi_{r}\right)= & v_{1}(p-w) q-\frac{v_{2} p q^{2}}{2(b-a)}+\frac{v_{1} m p q}{b-a} \\
& +\alpha h(1-k) q+v_{3}(w-c) q .
\end{aligned}
$$

The manufacturer's profit is

$$
E\left(\pi_{m}\right)=\left(v_{4}-v_{3}\right)(w-c) q-\alpha h(1-k) q .
$$


Theorem 4. There is a unique optimal order quantity and wholesale price maximizing the expected profit function. The optimal policies are as follows:

$$
\begin{aligned}
q^{*}= & \frac{v_{1}(p b-c b+c a)}{2 p v_{2}}+\frac{\alpha h(1-k)(b-a)\left(v_{4}-v_{1}\right)}{2 p v_{2}\left(v_{4}-v_{3}\right)}, \\
w_{*}= & \frac{\left(2 v_{3}-v_{1}\right) c}{2\left(v_{3}-v_{1}\right)}+\frac{v_{1} b p}{2\left(v_{1}-v_{3}\right)(b-a)} \\
& +\frac{\alpha h(1-k)\left(v_{4}+v_{1}-2 v_{3}\right)}{2\left(v_{4}-v_{3}\right)\left(v_{1}-v_{3}\right)}, \\
E\left(\pi_{r}\right)= & {\left[\frac{v_{1}(p b-c b+c a)}{4(b-a)}+\frac{\alpha h(1-k)\left(v_{4}-v_{1}\right)}{4\left(v_{4}-v_{3}\right)}\right] q^{*}, } \\
E\left(\pi_{m}\right)= & {\left[\frac{v_{1}\left(v_{4}-v_{3}\right)(p b-c b+c a)}{2(b-a)\left(v_{1}-v_{3}\right)}\right.} \\
& \left.+\frac{\alpha h(1-k)\left(v_{4}-v_{1}\right)}{2\left(v_{1}-v_{3}\right)}\right] q^{*} .
\end{aligned}
$$

Proof. Refer to the proof of Theorem 1.

Proposition 3. Compared with the manufacturer's individual insurance, the order quantity of the retailer increased when sharing the premium, and the profit of both the manufacturer and the retailer was higher than that of the manufacturer's individual insurance.

\section{Numerical Examples}

In this section, we present numerical examples to illustrate how managers apply our models to the risks of disruption in practice; the example problems are accompanied by sensitivity analysis and derive some managerial insights that can guide managers to make decisions. We use MATLAB to carry out numerical simulation; when the market demand for the retailer obeys uniformly distribution $[0,1000]$, $p=100, c=10, h=50, r=0.02, k=0.5, \beta=0.2$, and $\gamma=0.5$. The optimal wholesale price of manufacturer is shown in Table 2 and Figure 1.

As can be seen from Table 2 and Figure 1, as the probability of interruption increases, manufacturers will increase the wholesale price to reduce the risk loss caused by interruption. In addition, we find that the wholesale price of manufacturer under separate insurance is lower than that under no insurance. This is because the manufacturer has transferred part of the interruption risk to the insurance company by purchasing insurance. The manufacturer stimulates the retailer to increase orders by lowering wholesale price. When the probability of interruption is quite low, the wholesale price of the manufacturer in the case of sharing insurance premium is lower than the wholesale price in no insurance, which indicates that when the probability of interruption is very low, the utility of the
TABLE 2: Optimal wholesale price of manufacturer.

\begin{tabular}{lccc}
\hline$\alpha$ & No insurance & Separate insurance & Sharing insurance \\
\hline 0.11 & 44.07 & 44.00 & 65.12 \\
0.13 & 44.87 & 44.75 & 66.16 \\
0.15 & 45.68 & 45.52 & 67.22 \\
0.17 & 46.50 & 46.29 & 68.31 \\
0.19 & 47.35 & 47.07 & 69.43 \\
0.21 & 48.21 & 47.86 & 70.58 \\
0.23 & 49.10 & 48.66 & 71.76 \\
0.25 & 50.00 & 49.46 & 72.97 \\
0.27 & 50.92 & 50.28 & 74.22 \\
0.29 & 51.87 & 51.11 & 75.50 \\
0.31 & 52.84 & 51.96 & 76.83 \\
0.33 & 53.83 & 52.81 & 78.19 \\
0.35 & 54.85 & 53.67 & 79.60 \\
\hline
\end{tabular}

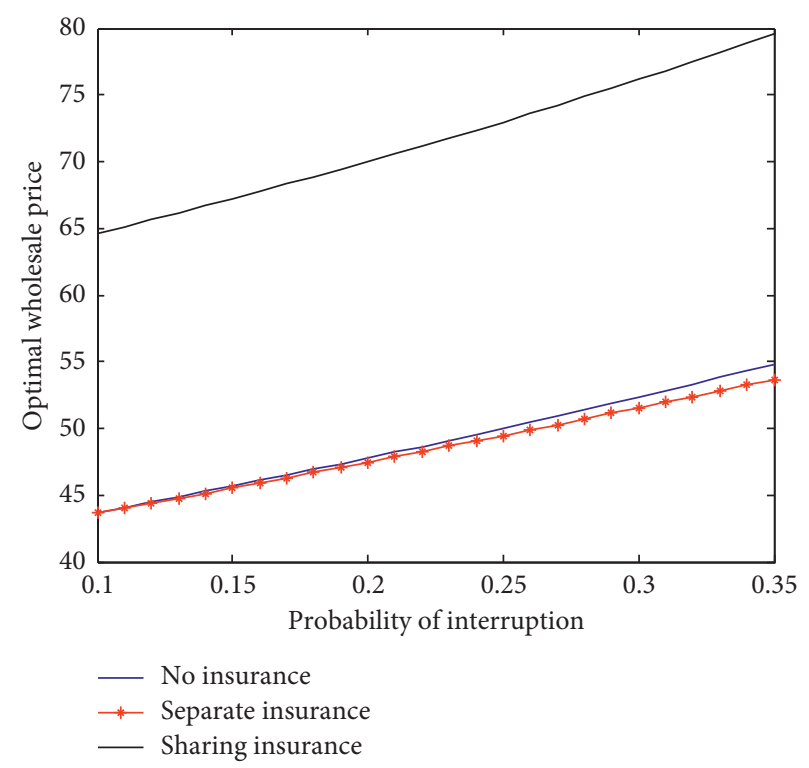

FIGURE 1: Impact of disruption probability on optimal wholesale price.

insurance company is not obvious. In this case, the manufacturer is bound to reduce the wholesale price to encourage the retailer to share the premium. When the probability of interruption is high, the retailer will share the premium and get the compensation from the insurance company, and the manufacturer will raise the wholesale price to make up for the loss.

Table 3 and Figure 2 indicate the relationship between manufacturer's profit and the change of interruption probability. From Table 3, we can know the following: (1) When the manufacturer does not buy insurance, his profit is a decreasing function of interruption probability, which is an intuitive observation. (2) The profit of the manufacturer increases with the interruption probability when the manufacturer purchases business interruption insurance. At this time, the role of BI insurance becomes prominent when the manufacturer's production equipment and other production equipment have a high probability of interruption; the risk can be transferred by purchasing BI insurance to make up for the loss caused by the interruption. (3) The 
TABle 3: Profit of manufacturer.

\begin{tabular}{lccc}
\hline$\alpha$ & No insurance & Separate insurance & Sharing insurance \\
\hline 0.11 & 15573.19 & 16208.77 & 16224.98 \\
0.13 & 15498.73 & 16335.53 & 16361.84 \\
0.15 & 15425.35 & 16472.94 & 16512.31 \\
0.17 & 15353.12 & 16621.57 & 16677.30 \\
0.19 & 15282.10 & 16782.04 & 16857.82 \\
0.21 & 15212.34 & 16955.03 & 17054.95 \\
0.23 & 15143.93 & 17141.25 & 17269.89 \\
0.25 & 15076.92 & 17341.49 & 17503.95 \\
0.27 & 15011.41 & 17556.59 & 17758.57 \\
0.29 & 14947.48 & 17787.48 & 18035.33 \\
0.31 & 14885.21 & 18035.15 & 18335.99 \\
0.33 & 14824.72 & 18300.69 & 18662.48 \\
0.35 & 14766.10 & 18585.29 & 19016.93 \\
\hline
\end{tabular}

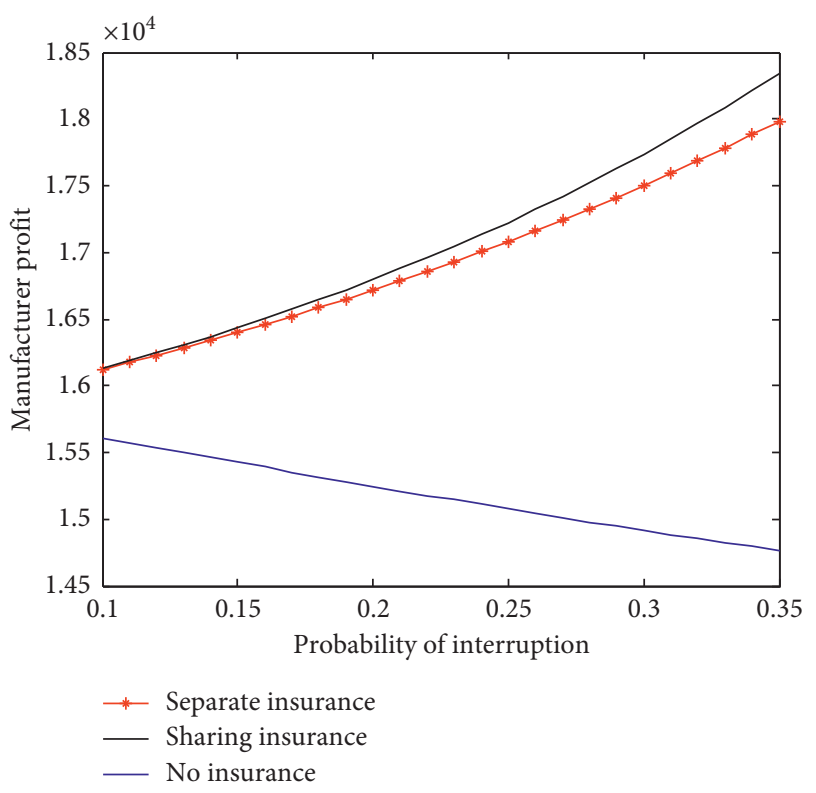

FIGURE 2: Impact of disruption probability on manufacturer's profit.

manufacturer's profit of buying insurance is always greater than that in the case of not buying insurance, and the greater the probability of interruption, the more obvious the effect of buying insurance. (4) As can be seen from Figure 2, with the increase of interruption probability, the manufacturer's profit in the case of sharing insurance premium is greater than that in the case of independent insurance, because coinsurance helps the manufacturer transfer part of the loss of interruption risk.

The following can be seen from Table 4 and Figure 3: (1) the order quantity of retailer is increasing in interruption probability, and when the probability of interruption is higher, the retailer needs to order more products to resist the risk of interruption. (2) The purchase quantity of the individual insurance is larger than that of the uninsured; after buying insurance, the manufacturer transfers part of the interruption risk to the insurance company, so the corresponding wholesale price is lower than that of the interruption without insurance, which will stimulate the retailer
TABLE 4: Order quantity of retailer.

\begin{tabular}{lccc}
\hline$\alpha$ & No insurance & Separate insurance & Sharing insurance \\
\hline 0.11 & 44.07 & 44.00 & 65.12 \\
0.13 & 44.87 & 44.75 & 66.16 \\
0.15 & 45.68 & 45.52 & 67.22 \\
0.17 & 46.50 & 46.29 & 68.31 \\
0.19 & 47.35 & 47.07 & 69.43 \\
0.21 & 48.21 & 47.86 & 70.58 \\
0.23 & 49.10 & 48.66 & 71.76 \\
0.25 & 50.00 & 49.46 & 72.97 \\
0.27 & 50.92 & 50.28 & 74.22 \\
0.29 & 51.87 & 51.11 & 75.50 \\
0.31 & 52.84 & 51.96 & 76.83 \\
0.33 & 53.83 & 52.81 & 78.19 \\
0.35 & 54.85 & 53.67 & 79.60 \\
\hline
\end{tabular}

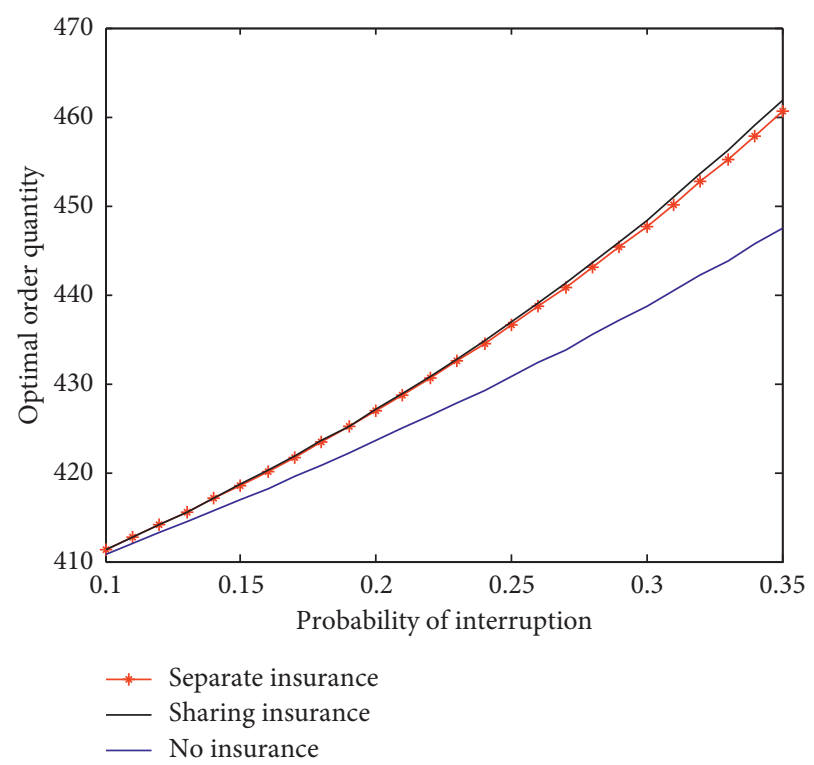

Figure 3: Impact of disruption probability on optimal order quantity.

to increase the order quantity. (3) We find that the optimal order quantity of the retailer in the case of sharing the premium is greater than the optimal order quantity of the retailer in the case of the manufacturer's individual insurance. Sharing premiums and insurance premiums can encourage retailers to order more quantity.

Table 5 and Figure 4 demonstrate the relative change in the retailer's profit with disruption probability. When the manufacturer is insured, regardless of the value of the interruption probability, the profit of the retailer will increase, and, with the increase of the interruption probability, the profit of the retailer is increasing. After buying BI insurance, the manufacturer will get some compensation for the loss, and he will reduce the wholesale price to stimulate the retailer to increase the order quantity. Through the transmission of the supply chain, the value of insurance is extended from the insured to the downstream uninsured enterprises, one enterprise insured, and two enterprises benefit, which achieve the effect of twice the result with half the effort. In addition, the insurance cost of retailers' optimal 
TABLE 5: Profit of retailer.

\begin{tabular}{lccc}
\hline$\alpha$ & No insurance & Separate insurance & Sharing insurance \\
\hline 0.11 & 7797.72 & 7798.00 & 7786.59 \\
0.13 & 7766.37 & 7766.88 & 7749.36 \\
0.15 & 7736.81 & 7737.67 & 7712.68 \\
0.17 & 7709.09 & 7710.42 & 7676.56 \\
0.19 & 7683.27 & 7685.23 & 7641.05 \\
0.21 & 7659.41 & 7662.19 & 7606.17 \\
0.23 & 7637.58 & 7641.38 & 7571.96 \\
0.25 & 7617.86 & 7622.90 & 7538.46 \\
0.27 & 7600.31 & 7606.87 & 7505.71 \\
0.29 & 7585.02 & 7593.40 & 7473.74 \\
0.31 & 7572.09 & 7582.60 & 7442.61 \\
0.33 & 7561.60 & 7574.62 & 7412.36 \\
0.35 & 7553.67 & 7569.59 & 7383.05 \\
\hline
\end{tabular}

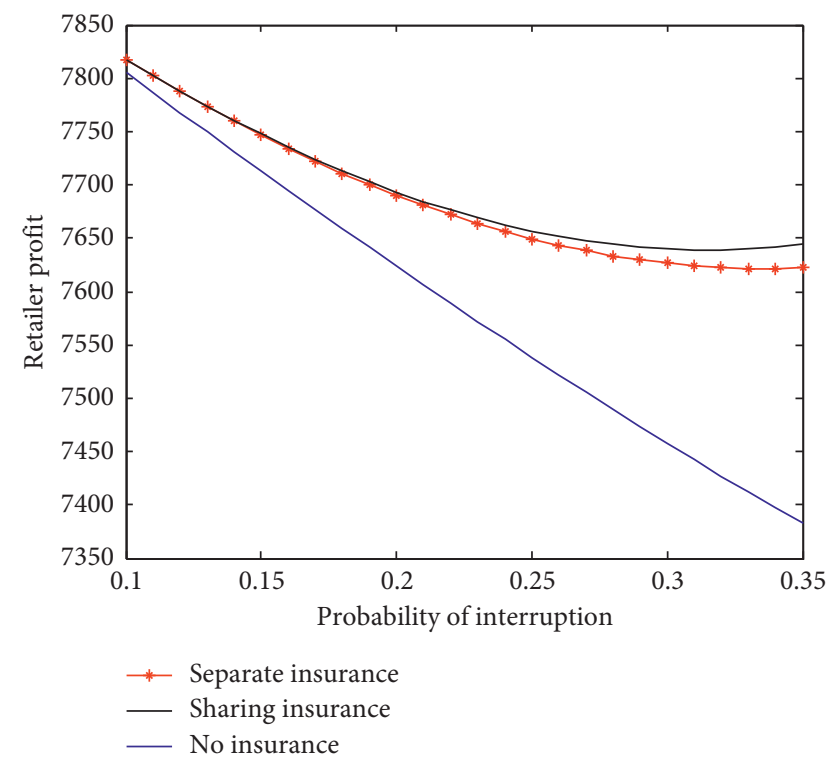

FIgURE 4: Impact of disruption probability on retailer's profit.

profits is greater than the individual insurance profits of retailers, and, with the increase of the interruption probability, the effectiveness of the BI insurance also enhanced, and retailer shares premium, not only helping manufacturers to transfer the risk but also obtaining insurance compensation by share premium.

The profits of manufacturer and retailer when $k=0.7$ and $k=0.2$ are shown in Figures 5-8.

From Figures 6-8, we can know that, regardless of the value of the supply factor, the profit of the manufacturer and the retailer after insurance is greater than the profit without insurance. The size of the supply factor does not affect the utility of insurance.

Through the above analysis, we can see that the manufacturer's profit increases with the probability of interruption no matter which way of insurance is adopted. In other words, when the probability of interruption is high, the manufacturer is better to choose to purchase $\mathrm{BI}$ insurance to transfer risks and make up for losses. However, no matter which kind of insurance is selected, the profit of the retailer

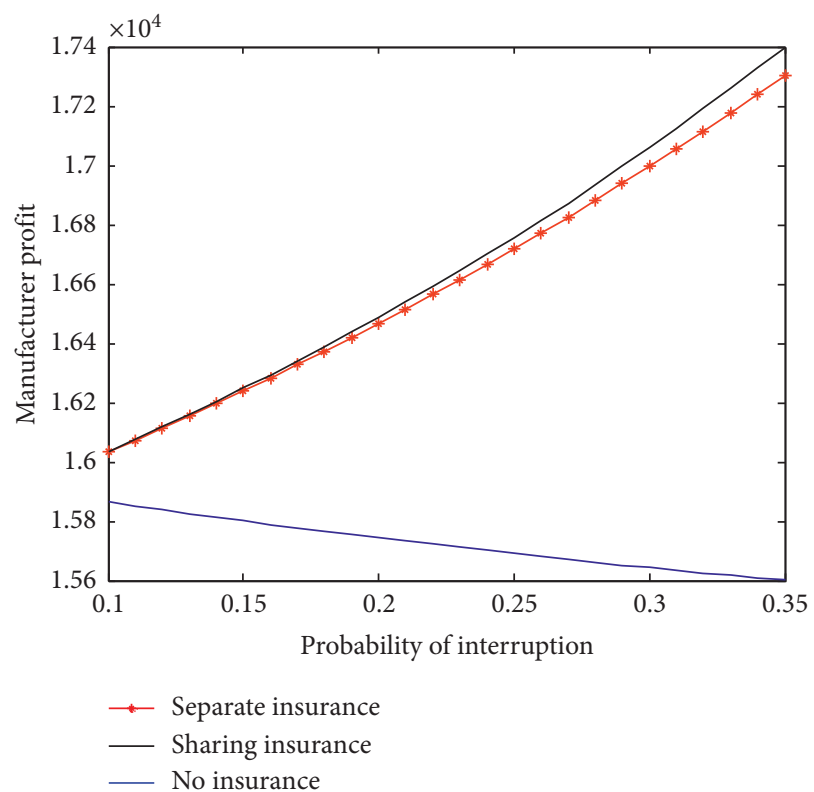

FIGURE 5: Impact of disruption probability on manufacturer's profit when $k=0.7$.

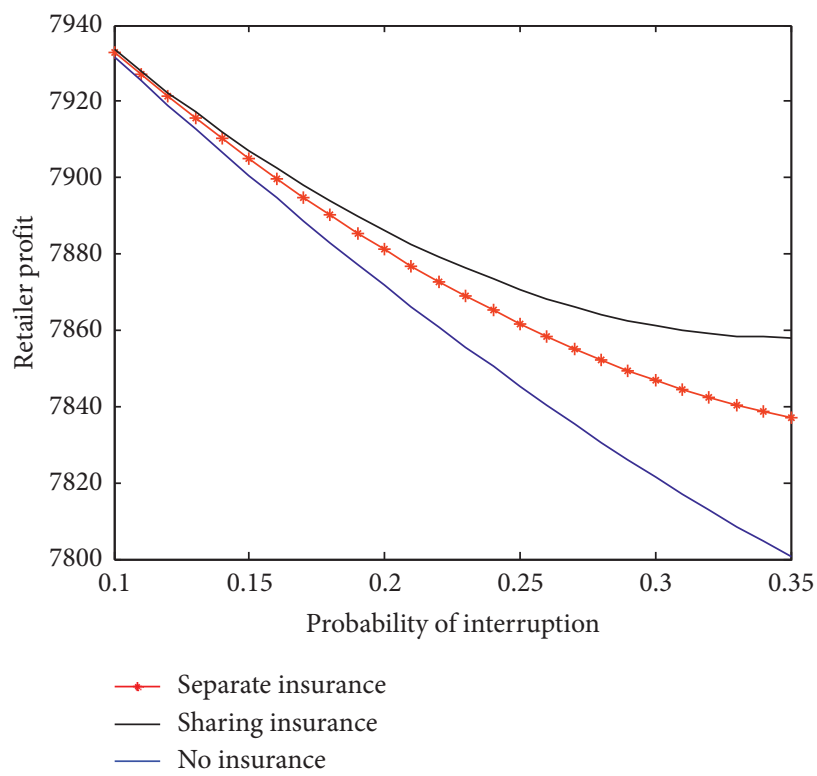

FIGURE 6: Impact of disruption probability on retailer's profit when $k=0.7$.

decreases with the increase of interruption probability. However, when the retailer is willing to share the insurance cost with the manufacturer, the profit of the retailer is still greater than that of the manufacturer alone. Secondly, for both manufacturer and retailer, the choice of sharing the premium is always better than the manufacturer of separate insurance. For retailer, the choice is to help manufacturer share part of the premium, and the manufacturer will share part of the premium income to retailers when interrupt occurs, equivalent to retailer passing on the risk of shortages to insurance companies to cover losses; the profit of both 


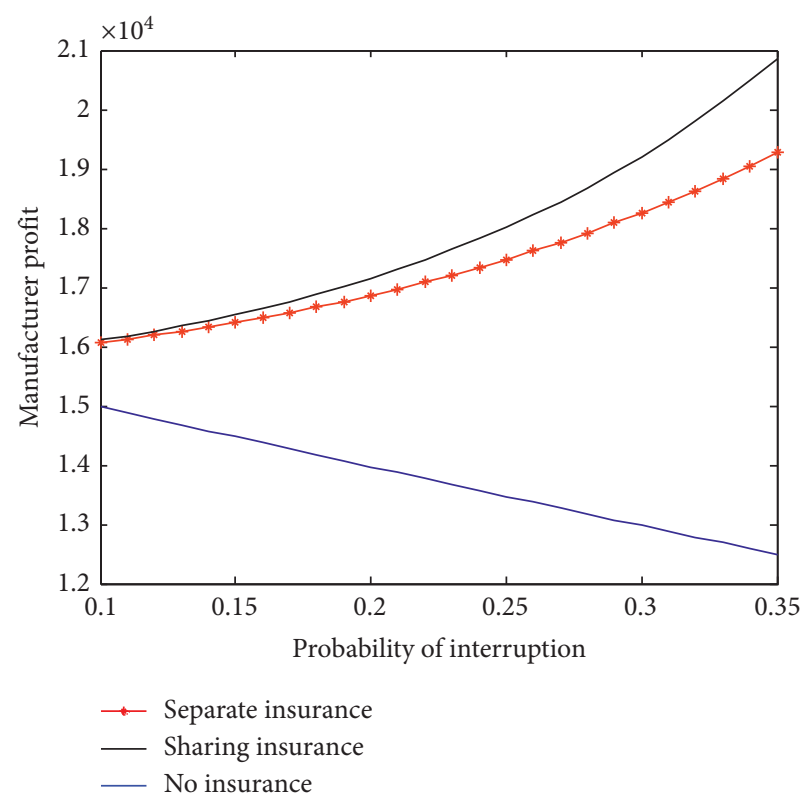

FIGURE 7: Impact of disruption probability on manufacturer's profit when $k=0.2$.

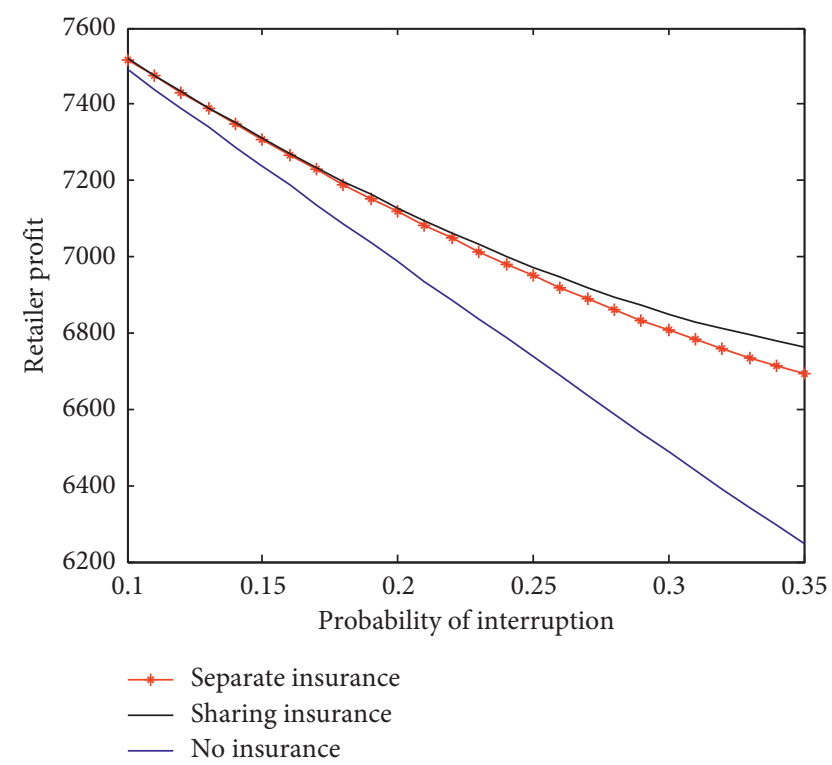

FIGURE 8: Impact of disruption probability on manufacturer's profit when $k=0.2$.

manufacturer and retailer can be increased by sharing premium and insurance compensation.

\section{Conclusion}

In this paper, we introduce $\mathrm{BI}$ insurance into the disruption model as a tool to manage interruption risk. We established four models, benchmark model, no insurance, manufacturer's individual insurance, and retailer's shared premium, to compare the optimal strategies of manufacturer and retailer under different probability of interruption risk. It is found that when the manufacturer is faced with interruption risk, it is better to choose buy insurance, and when the probability of interruption is higher, the effect of insurance is more obvious, and the manufacturer transfers part of the interruption risk to the insurance company through the purchase of insurance. Moreover, when the manufacturer purchased the insurance separately, the order quantity and profit of the retailer increased, and the utility of the insurance was transmitted from the upstream enterprise to the downstream retailer through the conduction effect of the supply chain. By sharing premiums and insurance payments with manufacturer, we find that the profits of manufacturer and retailer are increased, and this mechanism can also motivate retailers to order more goods. There are still many deficiencies in our research; for example, we consider that the demand is subject to specific uniform distribution and the risk attitude of the enterprise is not taken into account. Future work will explore the normal distribution of demand and the decision of manufacturers under different risk attitudes.

\section{Data Availability}

No data were used to support this study.

\section{Conflicts of Interest}

The authors declare that they have no conflicts of interest.

\section{References}

[1] E. Furman and R. Zitikis, "Weighted premium calculation principles," Insurance: Mathematics and Economics, vol. 42, no. 1, pp. 459-465, 2008.

[2] L. Dong and B. Tomlin, "Managing disruption risk: the interplay between operations and insurance," Management Science, vol. 58, no. 10, pp. 1898-1915, 2012.

[3] L. Dong, S. Tang, and B. Tomlin, "Production chain disruptions: inventory, preparedness, and insurance," Social Science Electronic Publishing, vol. 27, no. 6, pp. 1251-1270, 2017.

[4] X. Zhen, Y. Li, G. Cai, and D. Shi, "Transportation disruption risk management: business interruption insurance and backup transportation," Transportation Research Part E: Logistics and Transportation Review, vol. 90, no. 6, pp. 51-68, 2016.

[5] K. E. Stecke and S. Kumar, "Sources of supply chain disruptions, factors that breed vulnerability, and mitigating strategies," Journal of Marketing Channels, vol. 16, no. 3, pp. 193-226, 2009.

[6] E. J. Lodree and S. Taskin, "An insurance risk management framework for disaster relief and supply chain disruption inventory planning," Journal of the Operational Research Society, vol. 59, no. 5, pp. 674-684, 2008.

[7] K. J. Tierney, "Business impacts of the northridge earthquake," Journal of Contingencies and Crisis Management, vol. 5, no. 2, p. 11, 1997.

[8] Z. Lin, C. Cai, and B. Xu, "Supply chain coordination with insurance contract," European Journal of Operational Research, vol. 205, no. 2, pp. 339-345, 2010.

[9] J. C. Serpa and H. Krishnan, "The strategic role of business insurance," Management Science, vol. 68, no. 2, pp. 384-404, 2016. 
[10] S. A. Yang and J. R. Birge, "Trade credit, risk sharing, and inventory financing portfolios," Social Science Electronic Publishing, vol. 64, no. 8, pp. 3667-3689, 2016.

[11] Z. Yang, G. Aydın, V. Babich, and D. R. Beil, "Supply disruptions, asymmetric information, and a backup production option," Management Science, vol. 55, no. 2, pp. 192-209, 2009.

[12] X. Hu, H. Gurnani, and L. Wang, "Managing risk of supply disruptions: incentives for capacity restoration," Production and Operations Management, vol. 22, no. 1, pp. 137-150, 2013.

[13] B. Tomlin, "On the value of mitigation and contingency strategies for managing supply chain disruption risks," Management Science, vol. 52, no. 5, pp. 639-657, 2006.

[14] S. Y. Tang, H. Gurnani, and D. Gupta, "Managing disruptions in decentralized supply chains with endogenous supply process reliability," Production and Operations Management, vol. 23, no. 7, pp. 1198-1211, 2014.

[15] V. Babich, A. N. Burnetas, and P. H. Ritchken, "Competition and diversification effects in supply chains with supplier default risk," Manufacturing \& Service Operations Management, vol. 9, no. 2, pp. 123-146, 2007.

[16] N. Aissaoui, M. Haouari, and E. Hassini, "Supplier selection and order lot sizing modeling: a review," Computers \& Operations Research, vol. 34, no. 12, pp. 3516-3540, 2007.

[17] A. Sarkar and P. K. J. Mohapatra, "Determining the optimal size of supply base with the consideration of risks of supply disruptions," International Journal of Production Economics, vol. 119, no. 1, pp. 122-135, 2009.

[18] P. L. Meena, S. P. Sarmah, and A. Sarkar, "Sourcing decisions under risks of catastrophic event disruptions," Transportation Research Part E: Logistics and Transportation Review, vol. 47, no. 6, pp. 1058-1074, 2011.

[19] A. Xanthopoulos, D. Vlachos, and E. Iakovou, "Optimal newsvendor policies for dual-sourcing supply chains: a disruption risk management framework," Computers \& Operations Research, vol. 39, no. 2, pp. 350-357, 2012.

[20] M. Lu, S. Huang, and Z. J. M. Shen, "Product substitution and dual sourcing under random supply failures," Transportation Research Part B, vol. 45, no. 8, pp. 0-1265, 2011.

[21] G. Li, Y. Kang, and M. Liu, "Dual-source procurement strategies for manufacturers with supply disruption risks," Journal of Intelligent \& Fuzzy Systems, vol. 33, no. 5, pp. 2637-2645, 2017.

[22] Z. Yin and C. Wang, "Strategic cooperation with a backup supplier for the mitigation of supply disruptions," International Journal of Production Research, vol. 56, no. 12, pp. 4300-4312, 2017.

[23] C. Wang and Z. Yin, "Using backup supply with responsive pricing to mitigate disruption risk for a risk-averse firm," International Journal of Production Research, vol. 56, no. 17, pp. 5669-5676, 2018.

[24] B. He, H. Huang, and K. Yuan, "Managing supply disruption through procurement strategy and price competition," International Journal of Production Research, vol. 54, no. 7, pp. 1980-1999, 2016.

[25] Q. Li and S. Zheng, "Joint inventory replenishment and pricing control for systems with uncertain yield and demand," Operations Research, vol. 54, no. 4, pp. 696-705, 2006.

[26] M. Parlar and D. Berkin, "Future supply uncertainty in EOQ models," Naval Research Logistics, vol. 38, no. 1, pp. 107-121, 1991.

[27] D. B. Khang and O. Fujiwara, "Optimality of myopic ordering policies for inventory model with stochastic supply," Operations Research, vol. 48, no. 1, pp. 181-184, 2000.
[28] Y.-W. Zhou, J. Li, and Y. Zhong, "Cooperative advertising and ordering policies in a two-echelon supply chain with riskaverse agents," Omega, vol. 75, pp. 97-117, 2018.

[29] B. Yan, Z. Jin, Y. Liu, and J. Yang, "Decision on risk-averse dual-channel supply chain under demand disruption," Communications in Nonlinear Science and Numerical Simulation, vol. 55, pp. 206-224, 2018.

[30] S. Zhao and Q. Zhu, "A risk-averse marketing strategy and its effect on coordination activities in a remanufacturing supply chain under market fluctuation," Journal of Cleaner Production, vol. 171, pp. 1290-1299, 2018. 